\section{Allgemeine Suchanalyse}

B. Güssregen

Merck KGaA, Darmstadt, Deutschland

Synonym(e) General unknown

Englischer Begriff general unknown; multi target screening (analysis)
Definition Qualitative Suchanalyse.

Beschreibung Bei der allgemeinen Suchanalyse wird in einer Patientenprobe ungerichtet nach toxischen Substanzen, Medikamenten oder Drogen gesucht. Die häufigsten Anwendungen sind Fälle von akuten Intoxikationen oder Todesfälle mit ungeklärter Ursache. Meist wird die Analyse mithilfe der - GC-MS, zunehmend aber auch mit hochauflösenden - LC-MS-Techniken durchgeführt. 